\title{
A educação ambiental como política pública para gestão integrada dos recursos naturais: um estudo de caso do município de Paragominas no estado do Pará
}

\section{Environmental education as public policy for the integrated management of natural resources: a case study of the municipality of Paragominas in the state of Pará}

Fidelis Júnior Martins Paixão - Mestre em Gestão dos Recursos Naturais e Desenvolvimento Local na Amazônia (PPGEDAM/NUMA/UFPA). Pesquisador do Programa Interdisciplinar Trópico em Movimento (UFPA). Especialista de Projetos em Draxos Consultoria e Gestão Ambiental Ltda. E-mail: fidelispaixao@yahoo.com.br.

Marilena Loureiro Silva - Doutora em Desenvolvimento Socioambiental pelo Núcleo de Altos Estudos Amazônicos (NAEA) da Universidade Federal do Pará (UFPA). Professora adjunta do Núcleo de Altos Estudos Amazônicos (NAEA) da Universidade Federal do Pará (UFPA). E-mail: marilenaloureiro@yahoo.com.br.

\section{Resumo}

Este artigo tem por objetivo analisar a educação ambiental como uma política pública implementada pelo município de Paragominas na gestão dos recursos naturais locais, como resposta à grave crise social, econômica, ecológica e cultural que aquela comunidade atravessou nas últimas décadas. Apesar de suas peculiaridades, esse município é um espaço geopolítico representativo da realidade ambiental e dos conflitos que o uso dos recursos naturais enseja na região amazônica. Sua resposta a essa crise tornou-se conhecida nacionalmente, merecedora de análise, que identificou e tipificou seus ciclos à luz das teorias sobre políticas públicas e da educação ambiental como campo de articulação entre o saber e a ética. Como resultado, são apresentados os ciclos pelos quais passaram essa política local e uma contribuição ao CONAMA (Conselho Nacional do Meio Ambiente) visando regulamentar programas de educação ambiental.

\section{Palavras-chave}

Educação Ambiental. Políticas Públicas. Gestão dos Recursos Naturais. Desenvolvimento Local.

\begin{abstract}
The objective of this article is to analyze environmental education as public policy implemented by the Municipality of Paragominas in the management of local natural resources, in response to the serious crises social, economic, cultural and ecological that this community has been experiencing in the last decades. Despite its peculiarities, this municipality is a geopolitical space representative of the environmental reality and conflicts that the use of natural resources causes in the Amazon region. Your response to this crisis became nationally known, worthy of analysis, which identified and typified its cycles in the light of public policy theories and environmental education as a field of articulation between knowledge and ethics. As a result, the cycles through which this local policy is passed and a contribution to the National Environmental Council are presented, aimed at regulating environmental education programs in environmental licensing procedures.
\end{abstract}

\section{Keywords}

Environmental Education. Public Policies. Natural Resource Management. Local Development. 


\section{INTRODUÇÃO}

Paragominas se tornou um município de referência nacional por ter enfrentado a dinâmica do desmatamento, a destruição ambiental e as crises sociais na Amazônia, tendo superado esse quadro a partir da mobilização de recursos internos e da decisão política de seus gestores públicos e da população, tornando-se um "Município Verde" premiado nacionalmente. O problema aqui apresentado é como a educação ambiental se constituiu como política pública e qual sua contribuição com o desenvolvimento local de Paragominas? O objetivo da pesquisa visou identificar os elementos de formulação, implementação e a relação dessa política com os demais instrumentos de gestão dos recursos naturais e políticas setoriais e sua contribuição ao desenvolvimento local.

A pesquisa, na modalidade qualitativa, bibliográfica e de campo, com abordagem de estudo de caso, buscou num primeiro momento identificar material teórico adequado. Seguiram-se as atividades de campo, com levantamento e análise documental dos instrumentos normativos municipais e materiais afins, tais como programas, relatórios e material didático produzido no município que incidem sobre a política de educação ambiental e gestão dos recursos naturais; com entrevistas apoiadas por roteiros semiestruturados e questões abertas, aplicadas aos principais agentes públicos envolvidos no programa e nas políticas municipais setoriais e lideranças dos movimentos sociais.

Este artigo apresenta, inicialmente, os pressupostos de uma educação ambiental que responde de forma consistente a um cenário de complexidade crescente, como política pública que consolide uma cidadania pautada num tipo de relacionamento entre humano e natureza e que supera a dicotomia clássica de origem cartesiana. Em seguida, o município de Paragominas é apresentado imerso no cenário amazônico que responde a dinâmicas, decisões e projetos formulados visando apenas ao interesse nacional e ao mercado externo, reservando um papel de "periferia da periferia" para a região. As definições, as tipologias e as construções de políticas públicas são discutidas na parte seguinte, com destaque para a formação do processo decisório, ou o ciclo de políticas públicas. Por fim, a Política Municipal de Educação Ambiental de Paragominas é analisada e apresentada nas diversas etapas do ciclo das políticas públicas, ressaltadas suas dinâmicas, arena política, conflitos e convergência. As considerações finais sintetizam os cômputos da pesquisa, apresentando como 
resultado elementos para uma proposta de resolução do Conselho Nacional do Meio Ambiente (CONAMA) que visa estabelecer as bases técnicas dos programas de educação ambiental.

\section{A EDUCAÇÃO AMBIENTAL COMO RESPOSTA EM UM CENÁRIO DE COMPLEXIDADE CRESCENTE}

A educação ambiental tem se proposto e se legitimado como uma prática educativa primordial para a construção de uma sociedade igualitária e de um meio ambiente ecologicamente equilibrado. Tal legitimação é fruto das lutas empreendidas pelos movimentos sociais que questionam o modelo dominante de organização da sociedade. Contudo, a educação ambiental é um processo em construção, não havendo conceituação consensual a seu respeito. Decorrem, em consequência, práticas educacionais muitas vezes reducionistas, fragmentadas e unilaterais da problemática ambiental e de uma abordagem despolitizada e ingênua (LOUREIRO, 2006).

Marcada pela tradição naturalista que fragmenta a análise da realidade e estabelece a dicotomia entre natureza e sociedade, a educação ambiental em seu surgimento se prestou a um papel de explicitar os processos físico-químicobiológicos dos fenômenos naturais, engendrada fortemente pelo objetivo preservacionista e movida pelo senso estético nos anos 1950, tendo evoluído posteriormente para o enfoque no bem-estar, a partir dos primeiros sinais da crise ecológica emitidos nos anos 1960-1970. Chega ao século atual assumindo o compromisso ético-político a partir de uma visão socioambiental complexa e interdisciplinar que analisa, pensa, organiza o meio ambiente como um campo de interações entre a cultura, a sociedade e a base física e biológica dos processos vitais, ou seja, o meio ambiente como espaço relacional, em que a presença humana, longe de ser percebida como extemporânea, intrusa ou desagregadora, aparece como um agente que pertence à teia de relações da vida social, natural, cultural e interage com ela (LOUREIRO, 2006, p. 70; BRASIL, 2013, p. 522).

São as tensões e formulações conceituais desses dois polos que estão em confronto na análise dos procedimentos de educação ambiental como política pública, tornando emergente a reflexão sobre conceitos aparentemente consensuais, como os de sustentabilidade, cidadania e até mesmo de uma educação ambiental que não explicita seus paradigmas. No dizer de Guimarães (2013), a homogeneização 
de uma categoria travestida em um falso consenso vela conflitos decorrentes de relações assimétricas de poder, que geram dominação/exclusão neste modelo de sociedade e retira o caráter crítico, problematizador e questionador desta categoria. Cabe também identificar as armadilhas paradigmáticas, como limitadoras da compreensão da complexidade da realidade e do potencial transformador da ação política e pedagógica de cada pessoa ou organização.

Ao atentar para o campo da análise de políticas públicas, sob a luz das tensões e das formulações conceituais de Guimarães (2013), cabe referir-se à proposição de Secchi (2011) de que a educação ambiental se caracteriza como uma política pública por possuir dois elementos fundantes: a intencionalidade pública e a resposta a um problema público. Numa abordagem multicêntrica, considerando como atores do campo dessa proposição as organizações privadas, os organismos multilaterais, as organizações não governamentais, as redes de políticas públicas juntamente com os atores estatais, protagonistas da proposição no estabelecimento da política de educação ambiental. Ainda segundo Secchi (2011), usando a tipologia de Lowi, a educação ambiental se caracteriza como uma política regulatória, em interconexão com elementos de políticas constitutivas.

Ao tratar do processo de gerenciamento de políticas públicas, Wu et al. (2014, p. 139-140) reconhecem que "poucas organizações do setor público estão preparadas para enfrentar problemas públicos complexos de uma forma integrada, coerente e adaptável". Para eles, os governos e os gestores públicos "precisam reconhecer as interligações complexas e inesperadas que existem e surgem entre os problemas públicos [...] definindo instituições e práticas que conduzam a responder as complexidades dos problemas que enfrentam e ajustálas" (WU et al., 2014, p. 139).

Os autores alertam que a integração de políticas públicas não deve ser confundida com eficácia, uma vez que as políticas podem ser eficazes sem ser integradas e que alcançar políticas públicas integradas é uma tarefa mais difícil do que alcançar políticas eficazes, uma vez que a criação de políticas integradas normalmente enfrenta um sistema segmentado de criação de políticas públicas em setores, com limitações de tempo e orientado politicamente em que órgãos responsáveis por setores específicos operam de forma isolada um do outro e, quando interagem, geralmente enfatizam mais as diferenças, que requerem permutas e ignoram as complementaridades e sinergias possíveis. Para esses autores, a integração das políticas públicas garante minimamente sua consistência 
e sinergia, possibilita a inovação e a proposição de medidas corretivas a partir desse processo sinérgico em que são identificadas novas oportunidades e, por fim, aumenta a transparência e a responsabilidade nas ações dos diferentes agentes envolvidos no processo.

Discutindo a construção de políticas públicas de educação ambiental para sociedades sustentáveis, Biasoli e Sorrentino (2015, p. 33) ressaltam que o problema central que se coloca "é o da recuperação do controle pelo cidadão, no seu bairro, na sua comunidade, sobre as formas do seu desenvolvimento, sobre a criação das coisas concretas que levam a que a nossa vida seja agradável ou não". Para eles, a solução estaria na aproximação entre o cidadão, os representantes comunitários dos diversos segmentos e a comunidade escolar com o poder público instituinte da política municipal de educação ambiental. Mediados por uma metodologia participativa que possibilite o conhecimento mútuo, socialize e compartilhe os saberes, fazeres e reflexões dos participantes, esse processo construtivo deveria visar a "formulação de um projeto político pedagógico (PPP) de forma participativa [que] além da caracterização da situação do município" expresse o "compartilhamento dos sonhos e o enunciado das utopias" (BIASOLI; SORRENTINO, 2015, p. 34), ou seja, a mediação de uma metodologia participativa, que ressalte o protagonismo e a integração dos atores sociais locais.

\section{PARAGOMINAS: UM TERRITÓRIO IMERSO NO CONTEXTO AMAZÔNICO E NACIONAL}

Paragominas é um município fundado em 1965 e possui um território de $19.330 \mathrm{~km}^{2}$, numa espacialidade que concentra a maioria das atividades econômicas desenvolvidas na Amazônia, tais como a criação de gado bovino, a exploração madeireira, o manejo florestal, o reflorestamento, o cultivo de soja e grãos e a mineração de bauxita. O município já foi o maior produtor de bovinos do estado do Pará de 1983 a 1992 e o maior polo de produção de madeira em tora de floresta nativa do Brasil, nas décadas de 1980 e 1990. Tem aumentado na última década a produção de grãos e o reflorestamento, tornando-se em 2007 o maior produtor paraense de milho, o quarto maior de soja e o quinto de arroz. Também tem se destacado na atividade de reflorestamento, com cerca de 50 milhões de árvores plantadas até 2008. A produção mineral tornou-se expressiva por meio da exploração de bauxita, com uma reserva estimada em 2 bilhões de 
toneladas, cuja exploração foi iniciada em 2007, e já no ano seguinte passou a responder por 10\% da produção anual de bauxita no estado (PINTO et al., 2009).

O município pode ser considerado representativo das dinâmicaseconômicas, sociais e culturais da Amazônia, pois sua dinâmica de desenvolvimento resulta da combinação de fatores como estar localizado às margens de um importante eixo rodoviário, a rodovia Belém-Brasília; sua ocupação territorial se beneficiou das políticas de ocupação da região amazônica entre as décadas de 1960 a 1980, com ampla oferta de terra e crédito subsidiado e incentivos fiscais para a pecuária; e, por contar com grandes estoques de recursos naturais de alto valor comercial, como a madeira e o minério (PINTO et al., 2009).

Em janeiro de 2008, Paragominas foi arrolado como um dos 36 municípios responsáveis pelo desmatamento do bioma amazônico, tornando-se área prioritária para ações governamentais de combate ao desmatamento ilegal, conforme estabelecido pelo Decreto no $\mathrm{n}^{\circ}$ 6.321/2007 (BRASIL, 2007), passando pela operação “Arco do Fogo”, em abril 2008, que consistiu numa força-tarefa de fiscalização realizada por Polícia Federal, IBAMA, Força Nacional e Secretaria de Estado de Meio Ambiente, visando combater ao desmatamento e à exploração de produtos e subprodutos florestais realizados de forma ilegal.

Com o impasse e os conflitos estabelecidos entre o setor produtivo que operava de forma ilegal nesses municípios arrolados como os maiores desmatadores da Amazônia, um poder público local comprometido com esses setores, e a ação incisiva do governo federal no combate a ilegalidade, Paragominas se destacou com uma postura propositiva que lhe outorgou projeção nacional, quando a administração municipal lançou em 2008 o projeto "Paragominas Município Verde", realizado numa parceria entre o poder público local, o setor empresarial, trabalhadores e pequenos proprietários, com os objetivos de adequar ambientalmente o município, proporcionando sua retirada da lista dos desmatadores, por meio da ação nos seguintes eixos estratégicos: (i) pesquisa técnico-científica; (ii) monitoramento mensal da cobertura florestal; (iii) capacitação de agentes locais para monitoramento e gestão ambiental; (iv) disseminação da educação ambiental nas escolas municipais; (v) ampliação das áreas de reflorestamento e de manejo florestal; e (vii) microzoneamento das propriedades rurais (PINTO et al., 2009, p. 15).

Como parte de sua resposta à crise e de afirmação de sua posição como "Município Verde", Paragominas criou o Programa Municipal de Educação 
Ambiental, em parceria com a mineradora VALE/Hydro e com a organização não governamental CEDAC (Comunidade Educativa), de São Paulo, quando os alunos das escolas municipais passaram a receber, de forma transversalizada, noções de meio ambiente. Os educadores locais também são capacitados pelo CEDAC, que repassa a metodologia a ser aplicada nas atividades escolares. Depoimentos públicos apontam que o ambiente escolar mudou, com os alunos assumindo uma maior responsabilidade na preservação do ambiente. Segundo o prefeito, é perceptível uma "visível mudança que a cidade sofreu e, principalmente as escolas, com o advento da educação ambiental [...] [com] a escola ajuda[ndo] a formar adultos mais educados e comprometidos com o ambiente onde moram" (SOUSA, 2016).

Torna-se importante e necessário compreender a posição do território de Paragominas em relação ao estado do Pará e à região amazônica no contexto geopolítico e econômico global. Contudo, inicialmente, deve ser ressaltado o aspecto histórico dessa inserção, a partir dos objetivos políticos nacionais.

Ainda que no debate ecológico a Amazônia costume ser identificada como um dos maiores bancos genéticos do planeta, na realidade ela continua como uma região periférica, de um país emergente, que abriga 10\% da população brasileira e contribui com exíguos 5\% para o PIB nacional. Mitschein et al. (2014) salientam que a partir dos anos 1950 a Amazônia se tornou objeto de um modelo de desenvolvimento denominado de "desequilibrado" e "corrigido". "Desequilibrado" por favorecer segmentos econômicos como os setores mineral, agropecuário e madeireiro, dos quais se esperavam vantagens comparativas no mercado global. "Corrigido" porque se previam intervenções a partir do Estado para mitigar os desequilíbrios que a implantação do modelo traria necessariamente em seu escopo.

Esse cenário é melhor compreendido tendo em conta que, no período pós-Segunda Guerra Mundial, os governos dos países considerados terceiromundistas adotaram políticas econômicas que tivessem como objetivo estratégico sua inserção no mercado global, visando a uma integração com a civilização industrial, de modo a superar o seu passado colonial com as mazelas sociais, econômicas e culturais. Para Mitschein et al. (2013), o discurso desenvolvimentista se deu no auge do "milagre econômico" na América Latina, quando havia abundância de capital financeiro nos países desenvolvidos, tendo os países terceiro-mundistas sido o mercado privilegiado para a entrada desses capitais por intermédio de empréstimos vultuosos, com a expectativa de que o aumento da produtividade geraria as condições para o pagamento das dívidas. 
Nos países do hemisfério norte, os novos movimentos sociais ganhavam força impulsionados pelo Relatório Meadows, intitulado "Os limites do crescimento" (COMISSÃO MUNDIAL SOBRE MEIO AMBIENTE E DESENVOLVIMENTO, 1991), dirigido ao Clube de Roma, e às discussões que floresciam e estabeleciam críticas às externalidades do processo produtivo industrial que afetavam o meio ambiente natural, tais como a chuva ácida, a destruição das florestas, os riscos no uso da fusão nuclear como fonte de energia, a poluição dos rios e oceanos, além da destruição acelerada da biodiversidade. Por conta da repercussão positiva em crescentes segmentos da população, esses movimentos sociais, apoiados por expressivos segmentos do mundo acadêmico, acabaram colocando na pauta política dos países do Norte, a questão ambiental como um desafio planetário, forçando acordos e programas internacionais de proteção das florestas tropicais (MITSCHEIN et al., 2013).

Porém, em que pesem tais iniciativas, a roda da economia girava para outra direção. Apesar de Estocolmo, do Relatório Brundtland (COMISSÃO MUNDIAL SOBRE MEIO AMBIENTE E DESENVOLVIMENTO, 1991) e da Rio-92 ressaltarem a necessidade de maior proteção das bases naturais da sobrevivência humana, o desmoronamento do sistema de Bretton Woods, os sucessivos e crescentes déficits da balança comercial dos Estados Unidos, acabando com a abundante oferta de capitais para o Terceiro Mundo, aliados ao Consenso de Washington, fizeram com que as instituições multilaterais como o Banco Mundial e o FMI negassem financiamento a países que não estivessem dispostos a diminuir a presença do Estado no âmbito da economia, extinguindo barreiras alfandegárias e abrindo seus mercados à concorrência internacional, colocando-se a reboque dos mercados globais (MITSCHEIN et al., 2013).

A Amazônia, até então apresentada como panaceia para o desenvolvimento nacional e para a balança comercial brasileira, passa a enfrentar um processo de "profunda polarização socioespacial" que configura um cenário de destruição da natureza, envolvendo, segundo Mitschein et al. (2013): a) tensões permanentes e choques violentos entre os diferentes atores sociais (madeireiros, mineradores, pecuaristas, sem-terra, populações tradicionais etc.) que disputam a apropriação dos recursos naturais; b) um crescente êxodo rural que vai gerar a favelização dos principais centros urbanos da região; e, c) altas taxas de desmatamento que vão transformar o Brasil no maior emissor de gases de carbono oriundos da destruição de florestas tropicais. 
Nesse contexto, a inserção do estado do Pará se dá de forma peculiar, pois contribuindo com modestos 2,1\% para o PIB Nacional, na área de exportação se apresentava como um ator relevante, por ocupar o $6^{\circ}$ lugar entre os estados brasileiros, alcançando um raio de 30 países importadores de produtos minerais, como ferro gusa, alumina calcinada e alumínio. Dessa forma, o Pará gera hard cash para o Brasil inteiro, mas está sendo prejudicado pela Lei Kandir (BRASIL, 1996), que, desde a segunda metade dos anos 1990, isenta de impostos os produtos para exportação. A pauta desses produtos é dominada pela mineração, pela indústria madeireira e pela pecuária, setores que têm se tornado os principais itens da economia paraense e também sido responsáveis pela polarização socioespacial, concentração da riqueza econômica e aprofundamento das desigualdades sociais entre e nos territórios do Pará (MITSCHEIN et al., 2013).

Contudo, a exploração de recursos naturais não renováveis, como minérios, por mais que esteja aumentando em escala vertiginosa, não garante que os territórios que os hospedem caminhem em direção à sustentabilidade social ou ambiental; pelo contrário, por serem de capital altamente intensivo, geram reduzidos efeitos de multiplicação de emprego e renda nesses territórios. A atividade pecuária, além de ter contribuído aceleradamente para o desmatamento, revela alta fragilidade para a economia regional, uma vez que, mesmo com o avanço da implantação de frigoríficos desde 2005, tem crescido a comercialização por meio da exportação do animal vivo, "boi em pé”, um negócio rentável para os criadores, mas prejudicial ameaçador para a economia paraense, por conta da isenção dos tributos, decorrente da Lei Kandir. Quanto ao setor florestal, o seu produto de maior valor agregado, a madeira serrada, responsável por 50\% da exportação do setor, torna o Pará o segundo maior fornecedor de madeira tropical do mundo, porém, segundo o IBAMA, mais de 70\% da exploração desse produto são provenientes de áreas não autorizadas, ou seja, madeira ilegal.

Para Mitschein et al. (2013), na medida em que o Estado brasileiro não pode "corrigir" os desequilíbrios que a política de desenvolvimento prevista no II PND trouxe para a região, o ônus da administração desses desequilíbrios foi transferido para as instâncias regional e local, buscando um revigoramento do "poder local e regional", substituindo a federalização do território por um processo de ações compartilhadas, entre diferentes níveis de governo e da constituição de novos territórios municipais, representando, também, um rearranjo das estruturas socioespaciais locais e do poder local (ROCHA; LIMA, 2009). 
Tal processo ganhava dinâmica por meio da "apropriação política do território e da atualização e/ou da constituição de identidades culturais como ponto de partida para construção de laços de união entre as populações de baixa renda e as classes dirigentes da esfera local" (MITSCHEIN et al. 2013, p. 65). Contudo, como esses processos se davam em função da crise do modelo de industrialização retardatária, os poderes locais e regionais revigorados em nenhum momento dispuseram dos meios técnicos e financeiros para promover políticas públicas com a correção das heranças decorrentes desse modelo.

\section{POLÍTICAS PÚBLICAS NUM CONTEXTO DE COMPLEXIDADE}

\subsection{A POLÍTICA PÚBLICA, SUAS TIPOLOGIAS E O PROCESSO DECISÓRIO}

Pode-se afirmar de forma resumida que a política pública se constitui como um campo de conhecimento que identifica o governo em ação, analisando suas características, propondo alterações em seu perfil e buscando entender como e por que as ações seguem determinados rumos. Para Souza (2003), o processo formulatório de políticas públicas se dá quando o governo traduz seus objetivos estratégicos em programas e ações, que, por consequência, produzirão resultados ou as mudanças desejadas na sociedade. Dessa forma, cabe aos estudiosos das políticas públicas compreenderem os mecanismos por meio dos quais os governos agem em determinada direção.

Já para Secchi (2011), a política pública se constitui como uma diretriz elaborada visando enfrentar um problema público. Em outras palavras, a política pública se constitui uma orientação à atividade do Estado ou da sociedade. Nessa perspectiva, pode-se entender que a política pública pode ser vista a partir de duas perspectivas: uma é a abordagem estatista, que considera as políticas públicas como monopólio dos atores estatais. Segundo esta abordagem, o que determina se uma política é ou não pública é a personalidade jurídica do ator protagonista. A outra perspectiva é a abordagem multicêntrica, onde atores não estatais podem ser provedores ou protagonistas na implementação das políticas públicas.

Ao se indagar do que trata a política pública, Saravia (2006, p. 28) assenta tratar-se de "um fluxo de decisões públicas, orientado a manter o equilíbrio social ou a introduzir desequilíbrios destinados a modificar essa realidade". Para ele, tais decisões são condicionadas pelo próprio fluxo e pela interação que gera 
reações e modificações provocadas na sociedade, sendo consideradas estratégicas quando apontam para fins desejados pelos diversos grupos sociais participantes do processo decisório.

É pertinente destacar que o conhecimento e a feitura de políticas públicas não são constructos prontos e acabados. Anterior a isto é preciso compreender o ponto de partida de como determinadas demandas são recepcionadas pelos tomadores de decisão e se tornarão em problemas públicos. Nessa perspectiva, podemos entender o processo decisório de políticas públicas, que passa por diversos estágios.

Monteiro (1982), um dos precursores em análise de políticas públicas no Brasil, considera que a literatura das chamadas ciências de decisão, ou processo decisório, costuma distinguir dois contextos em que se processam as decisões: a) a oportunidade, que se constitui na possibilidade de a política ser estabelecida voluntariamente pelo policy maker, com reduzida ou ausente pressão de grupos de interesse e uma consequente flexibilidade no tempo de implementação dessa política, possibilitando maior conhecimento do problema e incorporação de diferente perspectivas e interesses; e, b) as conjunturas de crise, em que as políticas são adotadas mais por pressão e provocação do que por vontade própria dos policy makers, com o tempo de ação tornando-se pouco flexível, passando o timing da política a ser um elemento importante a ser considerado, com baixa capacidade de definir e caracterizar o problema sobre o qual se pretende atuar e condições restritivas para incorporação de diferentes visões e perspectivas dos atores sobre o problema e as soluções propostas.

É possível visualizar a formação do processo decisório, ou o ciclo de políticas públicas, de acordo com Secchi (2011), nas seguintes etapas: uma vez identificado o problema (a discrepância entre a situação vivida e uma situação ideal requerida), que entrará para a agenda governamental, segue-se a formação da agenda política (conjunto de problemas ou temas que a comunidade política percebe como merecedor de atenção e intervenção pública) e governamental ou institucional (quando se elenca os problemas ou temas que o poder público decide enfrentar). $\mathrm{Na}$ formulação de políticas, as possíveis soluções, objetivos e metas são construídas, seguindo-se a tomada de decisões, momento em que os interesses dos diversos atores envolvidos no problema são equacionados e as intenções de enfrentamento do problema público são explicitadas. Já a implementação se constitui na fase em que as regras, rotinas e processos sociais são convertidos de 
intenções em ações, incidindo diretamente sobre a situação-problema. Segue-se a avaliação como o processo de julgamento sobre a validade das ações públicas, podendo se dar antes da implementação, durante a implementação ou após a implementação, cabendo critérios como economicidade, eficiência, eficácia e equidade, entre outros, na avaliação.

Para o estudo e análise das políticas públicas é relevante compreender o conceito de atores sociais. Segundo Secchi (2011, p. 77), "são os atores que conseguem sensibilizar a opinião pública sobre problemas de relevância coletiva", constituindo-se de indivíduos, grupos e organizações que desempenham um papel na arena política. São eles que influenciam nas decisões sobre o que entra ou sai das agendas política e institucional, que estudam propostas, tomam decisões e fazem com que intenções se tornem em ações. Atores individuais podem ser políticos ou pessoas de expressão pública, formadores de opinião, que agem na arena política, já os atores coletivos são grupos e organizações, que agem intencionalmente na arena política. O autor destaca que a expressão intencionalmente serve para denotar a distinção entre atores não coordenados, daqueles que agem com intenção e motivação. Atores sociais nem sempre possuem comportamento e interesses em comum, podendo muitas vezes um determinado ator social ter diferentes intenções em diferentes contextos ou fases de elaboração da política pública, assim como interesses conflitantes com os demais atores da arena política.

Afinal, quem decide? Essa indagação remete a uma relevante questão, que é do tipo de participação dos atores sociais na arena política. $\mathrm{Na}$ análise de políticas cabem principalmente duas abordagens sobre participação: o modelo elitista e o modelo pluralista, ainda segundo Secchi (2011). O elitismo parte da visão de que poucos atores têm a capacidade de determinar os rumos das políticas públicas, havendo o predomínio de alguns setores da sociedade sobre outros. Já o modelo pluralista deixa de apontar a predominância de um ator ou de um conjunto de atores, concluindo que todos conseguem influenciar, de alguma maneira a arena política, cada um com seus recursos e capacidade organizativa. Em algumas arenas alguns recursos são mais valiosos que outros, ou determinados recursos estão disponíveis para determinados atores, mas lhes falta o interesse em utilizá-los. Contudo, num sistema desigual social e economicamente, colocam-se dúvidas quanto à capacidade de mobilização e de influência dos vários atores na arena política.

Ao se atentar especificamente para a realidade amazônica no contexto das políticas públicas implementadas pelo poder central, pode-se, à luz de Becker (1993), identificar o esgotamento do projeto nacional geopolítico que promoveu a 
ocupação da região nas décadas de 1960 a 1980, quando a Amazônia foi encarada como a grande fronteira para promoção de um novo padrão de inserção do Brasil no cenário internacional, alvo de interesses internacionais conflitantes e submetida a um processo de ocupação predatória.

Ao analisar o contexto nacional do Brasil em 2012, quando da realização da Rio+20 - Conferência das Nações Unidas sobre Desenvolvimento Sustentável, Bezerra (2015) ressalta que esse contexto era bem distinto daquele de 1992, pois no ano de 2005 o país sofreu o maior índice de desmatamento da Amazônia desde os anos 1980, com o governo iniciando uma série de mudanças na governança ambiental, com elaboração do Plano de Ação para a Prevenção e Controle do Desmatamento na Amazônia Legal (PPCDAm), identificando os municípios com maior taxa de desmatamento e adotando uma série de medidas para reversão dessas taxas.

\subsection{A INTEGRALIDADE E A COMPLEXIDADE DA RESPOSTA DE PARAGOMINAS AOS DESAFIOS PROPOSTOS}

Visando analisar como Paragominas respondeu ao desafio de superar a crise em que estava imersa, partiremos do ciclo de políticas públicas, proposto por Secchi (2011).

\subsubsection{A identificação do problema}

Paragominas possui uma espacialidade que concentra a maioria das atividades econômicas desenvolvidas na região amazônica. Segundo Bergamin (2015), a dinâmica econômica local pode ser resumida nos Ciclos da Pecuária, nas décadas de 1970-1980; da Madeira, nas décadas de 1980-1990; e do Carvão Vegetal, nos anos 1990.

Por volta de 2005-2006 a economia local, baseada na exploração madeireira e na produção de carvão vegetal, começa a demonstrar os sinais de colapso, com a extinção dos recursos naturais até então abundantes. A intensificação da fiscalização pelos órgãos ambientais e o aumento das exigências, decorrentes da necessidade de diminuir as taxas de desmatamento na Amazônia, somam-se a esse fator, dando maior contorno a crise econômica local. Para se compreender a gravidade do momento, a autora relata que o cenário social era tão caótico, que conferiu à cidade o apelido de "Paragobala", numa alusão ao alto índice 
de homicídios, decorrente das disputas pela posse da terra, trabalho escravo e banditismo por conta dos conflitos urbanos.

A dramaticidade da situação local, descrita por Bergamin (2015), pontua que a assistência social local era meramente decorativa, de baixo impacto sobre as necessidades e problemas, o índice de evasão escolar alarmante, com escolas tão desestruturadas que sequer tinham carteiras para os alunos sentarem, uma única unidade de saúde operada pelo governo estadual com apenas atendimento básico, inexistência de abastecimento de água para a maioria dos bairros e graves problemas de acidentes no trânsito. A autora ressalta que "com problemas sociais e ambientais gravíssimos no município, a população de Paragominas começou a se mobilizar para dar um novo rumo àquela situação. (...) Foi o início de uma transformação jamais imaginada" (BERGAMIN, 2015, p. 42).

No ano de 2006 um conjunto de fatores se somaram ao cenário já desenhado. Medidas governamentais nacionais de combate ao desmatamento; a "moratória da soja", por produtores nacionais, junto com Organizações Não Governamentais (ONGs) ambientalistas e setores governamentais, visando eliminar de sua cadeia produtiva o desmatamento, o que levou a que a principal empresa compradora da soja do município anunciasse o fim de sua atividade comercial com os plantadores locais; medidas judiciais da Corregedoria de Justiça determinando bloqueio de inúmeras matrículas de imóveis, afetando a possibilidade de acesso ao crédito bancário por parte dos produtores rurais; e, por fim, em 2008, a inclusão do município na lista dos que mais desmataram o bioma amazônico, tornando-se área prioritária para ações governamentais de combate ao desmatamento ilegal.

\subsubsection{A formação da agenda}

O agravamento das condições socioeconômica e ambiental produziu a inquietação da comunidade, levando o prefeito a iniciar uma série de encontros e reuniões setoriais com o setor produtivo e a sociedade local, especialmente os sindicatos representativos do setor produtivo, com uma assembleia geral ocorrendo em fevereiro de 2008, sob clima de tensão e revolta por conta das ações repressivas do Estado. "Ademais, além de ter que encontrar medidas para solucionar os problemas que engessavam a economia, era necessário empreender esforços coletivos para que o município atendesse aos [principais] critérios do [Ministério do Meio Ambiente] para sair da lista” (BERGAMIN, 2015, p. 81). 
O prefeito apresentou à assembleia geral a proposta de conter o avanço do desmatamento, que denominou de Pacto pelo Desmatamento Zero, recebida com "muita relutância e ponderações" pelas entidades que concordaram por aderir ao pacto, comprometendo-se em não abrir novas áreas de florestas para atividades agrícolas, de pecuária ou atividades correlatas (BERGAMIN, 2015, p. 81).

\subsubsection{Formulação de políticas}

Essa autora segue relatando que visando prosseguir com as ações para retirar o município da lista do que mais desmataram a Amazônia, um mês após a assembleia, entidades representativas dos vários segmentos sociais, políticos e econômicos locais, tais como a Câmara Municipal de Vereadores, o Sindicato dos Trabalhadores Rurais, além das entidades anteriormente citadas e outras dezenas de entidades locais, assinaram o Pacto pelo Produto Legal e Sustentável, objetivando a produção sustentável e o desmatamento zero. Também nesse evento a Prefeitura e a Secretaria de Estado do Meio Ambiente assinaram um Termo de Cooperação Técnica para elaboração do Plano Municipal de Prevenção e Combate ao Desmatamento, que contemplou entre seus seis eixos de atuação a disseminação da educação ambiental nas escolas.

\subsubsection{Tomada de decisões}

Com o lançamento do Projeto Paragominas Município Verde, começaram os esforços para implementar os eixos estabelecidos no termo de cooperação técnica. Aqui cabe ressaltar que uma política pública dessa magnitude foi estabelecida com base num pacto de diversos atores locais, tendo como protagonista o Poder Executivo Municipal, porém sem criar mecanismos legais adequados para sua inserção nos órgãos e organismos administrativos da gestão pública, como por exemplo, leis, decretos, organogramas e instrumentos afins. Bergamin (2015) noticia a existência de um decreto municipal, porém restrito a um dos eixos do pacto assinado, determinando no plano decenal municipal a meta de que para cada habitante deveria haver $12 \mathrm{~m}^{2}$ de área verde plantada. Parcerias foram estabelecidas, visando à qualificação técnica, o levantamento e o monitoramento de dados.

Na sequência dos acontecimentos, novas turbulências eclodiram em abril de 2008, quando a Operação Arco de Fogo levou ao embargo de 100 propriedades rurais, multas aplicadas com valor total superior a $\mathrm{R} \$ 50$ milhões e fechamento de 
dezenas de serrarias e carvoarias no município. Em novembro do mesmo ano, novas medidas repressivas são tomadas por meio da Operação Rastro Negro, fechando ainda mais carvoarias, destruindo mais de 800 fornos de carvão e apreendendo 18 caminhões cheios de toras de extratores de madeira clandestina.

A revolta do segmento produtivo que vivia dessas práticas ilícitas, somada com os trabalhadores desempregados, renderam uma iniciativa de insurgência, quando os proprietários dos caminhões apreendidos retiraram esses veículos do pátio do IBAMA e incendiaram a sede do órgão, iniciando inclusive uma ação para incendiar o hotel onde os agentes ambientais federais se encontram hospedados, no que foram contidos pela Polícia Militar. Com a repercussão nacional imediata, o Prefeito reuniu as entidades e segmentos políticos comprometidos com o Pacto estabelecido anteriormente e juntos expediram uma carta à nação repudiando os acontecimentos e desaprovando a atitude daquela parcela da população, relata Bergamin (2015), iniciando uma série de passos políticos de ida a Brasília, visita ao Ministério do Meio Ambiente e vinda do ministro ao município, visando conhecer de perto a situação, possibilitando um diálogo produtivo entre os poderes local e federal, com o lançamento da "Operação Arco Verde”, de caráter preventivo, envolvendo assistência técnica, crédito, transferência de tecnologia e agilização na regularização fundiária.

\subsubsection{Implementação}

O Programa de Formação de Professores em Educação Ambiental foi instituído em 2008 com a finalidade de capacitar docentes da rede pública municipal para tratar a temática ambiental como um tema transversal no desenvolvimento de seu trabalho cotidiano com os alunos e promover a adoção de práticas ambientalmente sustentáveis por alunos e professores nos diferentes espaços de convivência. Inicialmente a oferta se restringia às disciplinas Língua Portuguesa e História, tendo se ampliado posteriormente para Geografia, Matemática e Artes (SEMEC, 2012).

No formato inicial, o programa compunha-se de 3 ações principais: um plano de trabalho a ser desenvolvido com os alunos, que seriam as Sequências Didáticas (SD), elaboradas com apoio de especialistas, baseadas no currículo e nos livros didáticos usados no município, trazendo os conteúdos da educação ambiental e orientações ao professor, apoiando as ações de formação; as Reuniões Gerais e as Oficinas, ambas bimestrais, para aprofundamento dos temas com especialistas da área e em educação ambiental, seguido do acompanhamento por coordenadores 
locais para análise e planejamento da ação didática. Concomitante, foram realizadas as Mostras de Educação Ambiental, com exposição dos trabalhos elaborados pelos alunos das escolas então envolvidas no programa (SEMEC, 2012).

A Lei Ambiental Municipal estabelece em seu art. 8o inciso VIII, que:

Compete ao Poder Executivo Municipal, por intermédio da Secretaria Municipal do Meio Ambiente e Urbanismo (SEMMA), e complementarmente às demais unidades político-administrativas do Município, no âmbito de suas competências legais: promover a educação ambiental formal, em conjunto com a Secretaria Municipal da Educação, a não-formal e a informal" (CÂMARA MUNICIPAL DE PARAGOMINAS, 2007, p. 5).

Não obstante, o programa foi implementado pela Secretaria Municipal de Educação, sem envolvimento do órgão ambiental local, conforme se depreende da fala do então coordenador da implantação do programa:

A Secretaria Municipal do Meio Ambiente cuidava dessa parte física da cidade, a coleta do lixo, a limpeza das áreas, projeto de arborização. A parte relacionada com educação ambiental ficou com a Secretaria Municipal de Educação". Na análise do entrevistado, a Secretaria do Meio Ambiente tinha uma visão tecnicista dos problemas, pois "eles davam mais a orientação de como plantar, como colocar os vegetais, como promover a arborização em torno da escola, mas nunca com o diálogo pedagógico (LEITE, 2016)

Na Secretaria Municipal do Meio Ambiente, inexiste um órgão responsável por coordenar suas ações que, quando ocorrem, são realizadas de forma pontual, além do problema comum nas demais unidades da Secretaria, que é a insuficiência de técnicos e sua baixa qualificação. Segundo o coordenador de licenciamento ambiental da Secretaria do Meio Ambiente, as ações de educação ambiental no licenciamento, quando a atividade é impactante, além das exigências cabíveis, "é exigido que o empreendedor realize ação de conscientização sobre o empreendimento com a vizinhança" (MENDES, 2016).

\subsubsection{Avaliação}

No Ciclo de Políticas Públicas, a avaliação é compreendida como o processo de julgamento sobre a validade das ações empreendidas, podendo se dar antes, durante ou após a implementação, cabendo critérios como economicidade, eficiência, eficácia e equidade, entre outros (SECCHI, 2011). No Programa de Paragominas não existe um momento de avaliação dessa importante política 
pública. O processo avaliativo geral é mais empírico e a avaliação sistematizada se restringe ao conteúdo ministrado na sala de aula, para averiguação da aprendizagem do aluno, conforme explica o coordenador local de Língua Portuguesa, da SEMEC que "mensurar, ter um sistema de avaliação da educação ambiental sistematizado, não temos. Essa avaliação é feita no dia-a-dia, a partir das mudanças de práticas. A avaliação que tem é feita dentro do conteúdo das disciplinas, nas provas, nos exercícios" (SOUZA, 2016).

Porém, é importante ressaltar que depoimentos públicos da coordenadora pedagógica da Secretaria Municipal de Educação apontam que o ambiente escolar mudou com os alunos assumindo uma maior responsabilidade na preservação do ambiente. Em depoimento, o prefeito, Paulo Tocantins, também aponta para uma visível mudança que a cidade sofreu e, principalmente as escolas, com o advento da educação ambiental, com a escola ajudando a formar adultos mais educados e comprometidos com o ambiente onde vivem (SOUSA, 2015). Também um dos gestores escolares corroborou essa percepção, afirmando que "o aluno começou a olhar para questões nunca olhadas: água, desmatamento, olhar para o seu quintal, para a rua. A escola foi fundamental na tomada de consciência e mudança de hábitos da população: limpeza, cuidado com o meio ambiente" (TITO, 2016).

Cabe ressaltar, contudo, que, ainda sobre o Programa Municipal de Educação Ambiental de Paragominas, não se percebe uma maior “aproximação das práticas culturais realizadas em diversos ambientes, na medida em que são essas práticas que estarão determinando o fazer pedagógico a ser desenvolvido nas escolas", como ressalta Silva (2014, p. 57-58), uma vez que "a educação escolar em sua estrutura programática teria muitíssimo o que aprender com a vida das comunidades das florestas, que conseguem estabelecer relações de integração com a natureza" (SILVA, 2014, p. 58)

Não se identificou no material pedagógico utilizado, especialmente nas sequências didáticas produzidas pelo programa, a "utilização de métodos que aproximem o saber formal, os conhecimentos contidos nos livros didáticos à cultura da comunidade e suas formas de organização para lidar com seus problemas e necessidades" (SILVA, 2014, p. 50), uma vez que processo pedagógico e educativo pode se fundamentar na "utilização dos recursos naturais presentes na floresta que passam a assumir para os professores, um papel de recursos didáticos: é a floresta que ensina, e ensina de modo interdisciplinar" (SILVA, 2014, p. 50). 


\section{RESULTADOS E CONSIDERAÇÕES FINAIS}

A pesquisa realizada para o estudo de caso de Paragominas propunha que seu resultado fosse enviado como elemento sugestivo à Câmara Técnica de Educação Ambiental do CONAMA, visando estabelecer as bases técnicas para regulamentar os programas de educação ambiental. Porém, adquiriu uma dimensão maior, ao resultar na formulação de projeto de resolução propondo a regulamentação dos Programas de Educação Ambiental, submetida a uma discussão coletiva no âmbito da Rede Brasileira de Educação Ambiental (REBEA), do Cadastro Nacional das Entidades Ambientalistas (CNEA), e do Fórum Brasileiro de Organização Não Governamentais (ONGs) e Movimentos Sociais para o Meio Ambiente e o Desenvolvimento (FBOMS), no período de janeiro a março 2016, a partir de uma minuta elaborada com suporte técnico do analista ambiental Alex Bernal, integrante da equipe do Departamento de Educação Ambiental (DEA), do Ministério do Meio Ambiente (MMA) (BERNAL, 2016).

Dessa forma, à luz da análise do caso de Paragominas relatado e analisado nesta pesquisa, pode-se ressaltar os seguintes aspectos que embasaram a proposta de resolução:

a) o PEAMB Paragominas foi financiado pelas empresas mineradoras Vale e Hydro. Um dos elementos identificados nesse financiamento foi a paralisação no percurso do programa, tendo posteriormente sido retomado. Geralmente as empresas financiam projetos e programas locais como parte da Compensação Ambiental devida, previstas no Licenciamento Ambiental. Nesse sentido, cabe regulamentar os Programas de Educação Ambiental decorrentes de exigências do Licenciamento Ambiental, de modo que o poder público possua instrumentos mais eficazes para elaborar os Termos de Referência e avaliar e monitorar a sua implementação.

b) há a necessidade de um diagnóstico socioambiental, a partir de instrumentos metodológicos adequados para coleta e análise de dados junto aos grupos que compõem a arena política e socioambiental local, especialmente com os objetivos de: (i) identificar e caracterizar problemas ambientais e conflitos que estejam direta ou indiretamente relacionados aos impactos do empreendimento em licenciamento; (ii) identificar e caracterizar potencialidades socioambientais encontradas nas localidades abrangidas pelo diagnóstico e (iii) identificar e caracterizar os sujeitos prioritários da ação educativa. 
c) o PEAMB deverá prever em seu escopo a identificação dos conflitos entre agentes da arena local, no uso de recursos naturais; das vulnerabilidades socioambientais; assim como as potencialidades socioambientais, de modo que sejam implementadas ações de fortalecimento da vocação e das dinâmicas socioeconômicas e culturais locais, num processo de empoderamento e protagonismo local.

d) as atividades da educação ambiental formal e não-formal devem estar integradas e realizadas de forma sistematizada, especialmente por meio de ações e práticas educativas voltadas à sensibilização da coletividade sobre as questões ambientais, à sua organização social e política e sua participação cidadã na promoção da qualidade do meio ambiente.

e) os projetos de educação ambiental passam a se integrar através de um Programa de Educação, com a criação de mecanismos participativos de acompanhamento e avaliação sistemática de sua implementação.

Ao avaliar o Programa de Educação Ambiental Municipal, observa-se que este foi implementado de forma não integrada às demais políticas setoriais, ficando restrito às salas de aula e ao processo pedagógico da educação escolar, em que pese sua influência ter sido capaz de afetar hábitos e valores culturais da comunidade. Contudo, a característica fragmentária fragiliza essa política pública e diminui sua capacidade de inserção nos demais segmentos da vida comunitária.

A educação ambiental como política pública em Paragominas deixou de se constituir em elementos e práticas de fortalecimento do protagonismo e de uma cidadania plena, crítica, apropriadora dos espaços públicos, para se tornar mais uma prática de referendo às diretrizes do poder político local.

O Programa de Educação Ambiental de Paragominas restringiu-se ao Programa de Formação de Professores em Educação Ambiental (SEMEC, 2012), uma vez que o órgão ambiental municipal sequer possui uma estrutura ou responsável pela coordenação das ações de educação ambiental, que são realizadas de forma pontual e não sistemática (MENDES, 2016).

Não foram criados instrumentos jurídicos que deem suporte ou um colegiado participativo que discuta, avalie e delibere de forma permanente o Programa de Educação Ambiental. Para o Programa de Formação de Professores são realizadas reuniões bimestrais que avaliam mais a prática pedagógica e os conflitos no ambiente escolar, do que o programa em si. Uma maior repercussão do programa e feedback com a comunidade decorreu das mostras realizadas para 
o público em geral com apresentação dos trabalhos escolares dos alunos e com a inclusão no planejamento escolar de ações de melhoria e sustentabilidade do ambiente interno da escola e seu entorno (SOUZA, 2016; TITO, 2016).

Mesmo em detrimento de suas fragilidades, as ações de educação ambiental no município tiveram forte capacidade de impacto na comunidade, especialmente na conscientização para o cuidado, a preservação e a valorização do meio ambiente urbano, com escolas mais limpas e práticas mais sustentáveis (SOUSA, 2015; SOUZA, 2016; TITO, 2016).

O aprofundamento e o aperfeiçoamento da implementação do Programa de Educação Ambiental de Paragominas, ao incorporar os mecanismos de integração intersetorial das diferentes políticas públicas, os instrumentos de avaliação institucional e os mecanismos jurídicos de controle acima apresentados, poderá qualificar essa iniciativa local como um referência para execução desse tipo de política de gestão ambiental em demais municípios, aliando a força de práticas educativas com os instrumentos de gestão e controle do poder público local.

\section{REFERÊNCIAS}

BECKER, B. A Amazônia pós ECO-92: por um desenvolvimento regional responsável. In: BURSZTYN, M. et al. (Orgs.). Para pensar o desenvolvimento sustentável. São Paulo: Brasiliense/ENAP, 1993, p. 129-143.

BERGAMIN, M. S. Paragominas: a experiência para se tornar um município verde na Amazônia. Belém: Marques Editora, 2015.

BERNAL, A. Proposta de resolução CONAMA [mensagem pessoal]. Mensagem recebida por<fidelispaixao@yahoo.com.br> em 14 jan. 2016.

BEZERRA, J. O Brasil na Rio+20: Qual foi o papel do País na Conferência das Nações Unidas sobre Desenvolvimento Sustentável? In: CASTRO, F. de; FUTEMMA, C. (Orgs.). Governança ambiental no Brasil: entre o socioambientalismo e a economia verde. Judiai: Paco Editorial, 2015.

BIASOLI, S.; SORRENTINO, M. Educação ambiental e municípios: políticas públicas para sociedades sustentáveis. In: RAYMUNDO, H.; BRIANEZI, T.; SORRENTINO, M. (Orgs.). Como construir políticas públicas de educação ambiental para sociedades sustentáveis. São Carlos: Diagrama Editora, 2015, p. 31-47.

BRASIL. Decreto n. 6.321, de 21 de dezembro de 2007. Presidência da República, Casa Civil, Subchefia para Assuntos Jurídicos. Brasília, 21 de dezembro de 2007. Disponível em: http://www.planalto.gov.br/ccivil_03/_ato2007-2010/2007/Decreto/D6321.htm. Acesso em: 14 abr. 2016. 
BRASIL. Lei n. 87, de 13 de setembro de 1996. Presidência da República, Casa Civil, Subchefia para Assuntos Jurídicos. Brasília, 13 de setembro de 1996. Disponível em: http://www.planalto.gov.br/ccivil_03/leis/lcp/lcp87.htm. Acesso em 14 abr. 2016.

BRASIL. Ministério da Educação. Diretrizes curriculares nacionais gerais da educação básica. Brasília: MEC, SEB, DICEI, 2013.

CÂMARA MUNICIPAL DE PARAGOMINAS. Lei Municipal n. 644, de 14 de dezembro de 2007 - Institui a Política Municipal do Meio Ambiente e dá outras providências. Paragominas: CMP, 2007.

COMISSÃO MUNDIAL SOBRE MEIO AMBIENTE E DESENVOLVIMENTO. Nosso Futuro Comum, $2^{a}$ edição. Rio de Janeiro: Editora da Fundação Getúlio Vargas, 1991.

GUIMARÃES, M. Por uma educação ambiental crítica na sociedade atual. Revista Interdisciplinar Margens, Abaetetuba, v. 7, n. 9, p. 11-22, set. 2013.

LEITE, T. A política de educação ambiental de Paragominas. [Entrevista concedida a] Fidelis Jr. Martins Paixão e Marilena Loureiro da Silva. Paragominas: 08 mar. 2016.

LOUREIRO, C. Educação ambiental e teorias críticas. In: GUIMARÃES, M. (Org.). Caminhos da educação ambiental: da forma à ação. Campinas: Papirus, 2006, p. 51 86.

MENDES, F. A política de educação ambiental de Paragominas. [Entrevista concedida a] Fidelis Jr. Martins Paixão e Marilena Loureiro da Silva. Paragominas: 08 mar. 2016.

MITSCHEIN, T.; CHAVES, J.; ESTUMANO, E. O Pará no século XXI e o desafio da educação profissionalizante. Belém: IEMCI/UFPA, 2014.

MITSCHEIN, T.; CHAVES, J.; ROCHA, G.; VASCONCELLOS, M. Desenvolvimento local e direito à cidade na floresta amazônica. Belém: NUMA/UFPA, 2013.

MONTEIRO, J. V. Fundamentos da política pública. Rio: IPEA/INPES, 1982.

PINTO, A.; AMARAL, P.; SOUZA JR., C.; VERISSIMO, A.; SALOMÃO, R.; GOMES, G.; BALIEIRO, C. Diagnóstico socioeconômico e florestal do município de Paragominas. Belém: Imazon, 2009.

ROCHA, G.; LIMA, A. A criação de novos municípios e o ordenamento territorial no estado do Pará. In: ROCHA, G. et al. (Org.). Territórios de desenvolvimento e ações públicas. Belém: EDUFPA, 2009, p. 209-230.

SARAVIA, E. Introdução à teoria da política pública. In: SARAVIA, E.; FERRAREZI, E. (Orgs.). Políticas públicas, coletânea. Brasília: ENAP, 2006, p. 21-42.

SECCHI, L. Políticas públicas: conceitos, esquemas de análise, casos práticos. São Paulo: Cengage Learning, 2011. 
SEMEC. Secretaria Municipal de Educação. Programa de formação de professores em educação ambiental. Paragominas: SEMEC, 2012.

SILVA, M. Revisitando o Programa de Desenvolvimento Sustentável da Floresta Modelo de Caxiuanã na ilha do Marajó. In: SILVA, M. (Org.). Políticas e práticas de educação ambiental na Amazônia. Belém: UFPA/GEAM, 2014, p. 43-60.

SOUSA, T. Paragominas promove $1^{\circ}$ Seminário do Programa de Educação Ambiental. 2015. Disponível em: http://encurtador.com.br/xJKY0. Acesso em: 20 jun. 2016.

SOUZA, C. Estado da arte da área de políticas públicas: conceitos e principais tipologias. In: ENCONTRO ANUAL DA ANPOCS, 27, 2003, Caxambu. Anais [...]. Caxambu: ANPOCS, 2003, p. 03-16.

SOUZA, C. A política de educação ambiental de Paragominas. [Entrevista concedida a] Fidelis Jr. Martins Paixão e Marilena Loureiro da Silva. Paragominas: 08 mar. 2016.

TITO, M. A política de educação ambiental de Paragominas. [Entrevista concedida a] Fidelis Jr. Martins Paixão e Marilena Loureiro da Silva. Paragominas: 08 mar. 2016.

WU, X.; RAMESH, M.; HOWLETT, M.; FRITZEN, S. Guia de políticas públicas: gerenciando processos. Brasília: ENAP, 2014. 
